\title{
Inhibition of Macrophage Activation and Lymphocyte Function of Annona vepretorum Mart. (Annonaceae) Natural Products
}

\section{Tatiana Barbosa dos Santos ${ }^{1,2}$, Cássio Santana Meira1, Cibele do Carmo Miranda ${ }^{3}$, Leociley Rocha Alencar Menezes ${ }^{3,4}$, Lívia Macedo Dutra ${ }^{4}$, Liviane do Nascimento Soares ${ }^{5}$, Andersson Barison $^{4}$, Emmanoel Vilaça Costa ${ }^{5}$, Elisalva Teixeira Guimarães ${ }^{1,2}$ and Milena Botelho Pereira Soares ${ }^{1,6 *}$}

\author{
${ }^{1}$ Gonçalo Moniz Research Center, Oswaldo Cruz Foundation (FIOCRUZ), Salvador, Bahia, Brazil \\ ${ }^{2}$ Department of Life Sciences, State University of Bahia, Salvador, Bahia, Brazil \\ ${ }^{3}$ Department of Chemistry, Federal University of Sergipe, São Cristóvão, Sergipe, Brazil \\ ${ }^{4}$ NMR Center, Federal University of Paraná, Curitiba, Paraná, Brazil \\ ${ }^{5}$ Department of Chemistry, Federal University of Amazonas, Manaus, Amazonas, Brazil \\ ${ }^{6}$ Center of Biotechnology and Cell Therapy, Hospital São Rafael, Salvador, Bahia, Brazil
}

*Corresponding author: Milena Botelho Pereira Soares, Centro de Pesquisas Gonçalo Moniz, Fundação Oswaldo Cruz 121, Rua Waldemar Falcão, Candeal-Salvador, Bahia-Brazil, 40296-710, Tel: +55 71 3176-2260, Fax: +55 71 3176-2272, E-mail: milena@bahia.fiocruz.br

\begin{abstract}
Immunomodulatory drugs are widely used for the treatment of inflammatory and immune-mediated conditions; however, their prolonged use is usually associated with the appearance of side effects and many immune disorders continuous without a suitable treatment. Natural products are an important source of therapies to a variety of illnesses. The present work investigated the immunomodulatory activity of a hexane extract and isolated compounds from Annona vepretorum Mart. Roots of $A$. vepretorum were used to produce a hexane extract, which was fractionated to obtain three diterpenes belonging to ent-kaurane series. The cytotoxicity of samples was determined using J774 macrophages. The immunomodulatory activity of natural products on macrophages activated with LPS and IFN- $\gamma$ was determined by evaluation of nitric oxide (NO) and cytokine production. The effects of samples on lymphocyte proliferation were evaluated using splenocyte cultures stimulated with concanavalin A or in mixed lymphocyte reaction (MLR), by assessment of ${ }^{3} \mathrm{H}$-thymidine incorporation. The production of IL-2 and IFN-y by lymphocytes was evaluated by ELISA. The effects of extract on the cell cycle progression of lymphocytes were evaluated by flow cytometry. The extract had low cytotoxicity and was able to modulate macrophages and lymphocytes in atoxic concentrations. AVHR (A. vepretorum hexane extract) significantly decreased NO, TNF- $\alpha$, IL-1 $\beta$ and IL- 6 production by activated macrophages. The extract also inhibited lymphocyte proliferation and IL-2 and IFN-y production by activated splenocytes. In a concentration-dependent manner, the hexane extract arrested cell cycle in G0/G1 phase, accompanied by an increase of cells in PreG1 phase. Isolated compounds also were capable for modulates macrophage activation and lymphocyte function. The present findings demonstrate a potent immunomodulatory activity of hexane extract from roots of $A$. vepretorum.
\end{abstract}

\section{Keywords}

Annona vepretorum, Immunomodulatory activity, Macrophage activation, Lymphocyte function, Annona vepretorum hexane extract

\section{Introduction}

Abnormal immune responses are involved in the initiation and development of a large number of diseases, including autoimmune diseases, allergies, cancer, immunodeficiency syndromes and neurodegenerative diseases [1,2]. Abnormalities on lymphocyte and macrophages functions are the key factors that trigger to the development and maintenance of immune-mediated diseases [3,4]. A variety of immunosuppressive drugs are currently available; however, due to side effects associated to a prolonged use and the inefficacy of conventional treatments in certain conditions, the search for new immunosuppressive drugs is needed.

Natural products constitute an important source of therapies to a large number of illnesses [5]. A number of studies have demonstrated the immunomodulatory effects of crude extracts of traditional herbal medicines and natural compounds [6-8]. Annona L. (Annonaceae) includes approximately 175 species of trees and shrubs distributed in lowland tropical regions [9]. The genus is well recognized by the nutritional use of their fruits and the use of different parts of the plant in folk medicine [10,11]. Previous chemical and pharmacological studies on some species of the genus have identified bioactive compounds (alkaloids, steroids, flavonoids, terpenoids) in roots, leaves, bark, seeds and fruits $[12,13]$. Isolated compounds, as well as crude extracts from different Annona species show biological

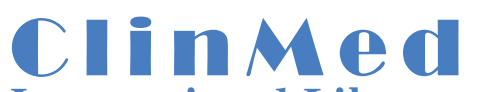

International Library

Citation: dos Santos TB, Meira CS, Miranda CC, Menezes LRA, Dutra LM, et al. (2016) Inhibition of Macrophage Activation and Lymphocyte Function of Annona vepretorum Mart. (Annonaceae) Natural Products. Int J Immunol Immunother 3:021

Received: April 18, 2016: Accepted: July 25, 2016: Published: July 27, 2016

Copyright: ( 2016 dos Santos TB, et al. This is an open-access article distributed under the terms of the Creative Commons Attribution License, which permits unrestricted use, distribution, and reproduction in any medium, provided the original author and source are credited. 
effects such as cytotoxicity against tumor cell lines, antimicrobial, antiprotozoal and immunomodulatory properties [11-15].

A. vepretorum Mart. (Annonaceae), popularly known as "bruteira", is a shrub or tree native from Brazilian biome Caatinga and is widely used in the human nutrition. In folk medicine, it has been used on bath to treat allergies, bites of bees and snakes and other inflammatory conditions [16]. Previous studies of this specie revealed a potent cytotoxicity activity of the essential oil from leaves of $A$. vepretorum in different cancer cell lines and an ethanolic extract of $A$. vepretorum showed antinociceptive and anti-inflammatory properties $[9,16,17]$.

The popular usage of this specie against inflammatory conditions and previous studies showing a suppressive effect on immune system suggest an immunomodulatory potential from A. vepretorum. In the present work, the immunomodulatory activity of a hexane extract and isolated compounds from roots of A. vepretorum Mart. on macrophage activation and lymphocyte function was investigated.

\section{Materials and Methods}

\section{Botanical material}

The roots of $A$. vepretorum were collected in the proximity of the city of Poço Redondo [coordinates: S $09^{\circ} 47^{\prime} 44.6^{\prime \prime} \mathrm{W} 37^{\circ} 40^{\prime} 35.3^{\prime \prime}$ ], Sergipe State, Brazil, in March 2013. The identity of the plant was confirmed by Dr. Ana Paula do Nascimento Prata, a plant taxonomist of Department of Biology from Federal University of Sergipe (UFS), Brazil and a voucher specimen (\#23158) has been deposited in the Herbarium of UFS. The authors have authorization from the Chico Mendes Institute for Biodiversity Conservation, and from Brazilian Ministry of the Environment for plant collection (\#25637-1).

\section{Extraction and isolation}

The dried and powdered of $A$. vepretorum $(839.0 \mathrm{~g})$ was successively extracted with hexane to yield hexane extract (AVHR; $34.90 \mathrm{~g}$ ). A part (5.0 g) of this extract was initially subjected to silica gel column chromatography $(\mathrm{CC} ; 2.5 \times 50.0 \mathrm{~cm})$ eluted with increasing concentrations of $\mathrm{CH}_{2} \mathrm{Cl}_{2}$ in $n$-hexane (100:0 to $10: 90, \mathrm{v} / \mathrm{v}$ ), followed by EtOAc in $\mathrm{CH}_{2} \mathrm{Cl}_{2}(100: 0$ at 20:80, v/v), and $\mathrm{MeOH}$ in EtOAc (100:0 to $50: 50, \mathrm{v} / \mathrm{v})$, affording 185 fractions ( $30 \mathrm{~mL}$ each). The eluted fractions were evaluated and pooled according to TLC analysis, to afford 33 groups (GF1 to GF33). Group GF16 (1650.5 mg) from $n$-hexane$\mathrm{CH}_{2} \mathrm{Cl}_{2}(20: 80$ and 100:0, v/v) was submitted to a new silica gel CC $(1.5 \times 40.0 \mathrm{~cm})$ eluted with increasing concentrations of $\mathrm{CH}_{2} \mathrm{Cl}_{2}$ in $n$-hexane $(100: 0 ; 80: 20 ; 60: 40 ; 20: 80$ and $40: 60, \mathrm{v} / \mathrm{v})$, followed by EtOAc in $\mathrm{CH}_{2} \mathrm{Cl}_{2}$ (100:0 to 80:20, v/v), affording 75 subfractions (30 $\mathrm{mL}$ each), that were evaluated and pooled according to TLC analysis, to afford 4 groups (GF16.1 to GF16.4). Group GF16.3 resulted in the isolation compound $1(1154.3 \mathrm{mg})$. Group GF19 $(271.6 \mathrm{mg})$ from $\mathrm{CH}_{2} \mathrm{Cl}_{2}$-EtOAc (90:10 and 80:20, v/v) was submitted to a new silica gel CC $(1.5 \times 40.0 \mathrm{~cm})$ eluted with increasing concentrations of $\mathrm{CH}_{2} \mathrm{Cl}_{2}$ in $n$-hexane (100:0 to $0: 100, \mathrm{v} / \mathrm{v}$ ), affording 62 subfractions ( $30 \mathrm{~mL}$ each), that were subsequently pooled to afford 4 groups (GF19.1 to GF19.4). Group GF19.3 afforded compound 2 (128.9 $\mathrm{mg})$. Group GF20 (287.1 mg) from $\mathrm{CH}_{2} \mathrm{Cl}_{2}$-EtOAc (80:20, v/v) was submitted to a new silica gel CC $(1.5 \times 40.0 \mathrm{~cm})$ eluted with increasing concentrations of $\mathrm{CH}_{2} \mathrm{Cl}_{2}$ in $n$-hexane (100:0;80:20;60:40 and 40:60, v/v), followed by EtOAc in $\mathrm{CH}_{2} \mathrm{Cl}_{2}$ (100:0 and 90:10, v/v), affording 31 subfractions $(30 \mathrm{~mL}$ each), that were subsequently pooled to afford 5 groups (GF20.1 to GF20.5). The group GF20.4 furnished compound $3(55.2 \mathrm{mg})$.

ent-kaur-16-en-19-oic acid (1): White needles ( $n$-hexane-EtOAc

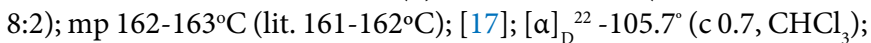
IR $(\mathrm{KBr}) v_{\max } 3479,2924,2868,1695,1470,1450,1262,1055,1035$, $1013,873 \mathrm{~cm}^{-1}$; ${ }^{1} \mathrm{H}$ and ${ }^{13} \mathrm{C}$ NMR data according to [18]; EI-MS $\mathrm{m} / \mathrm{z}$ $302[\mathrm{M}]^{+}$.

ent-3ß-hydroxykaur-16-ene (2): White solid ( $n$-hexane-EtOAc

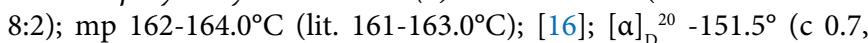
$\left.\mathrm{CHCl}_{3}\right) ; \mathrm{IR}(\mathrm{KBr}) v_{\max } 3345(\mathrm{OH}), 3070,2924,2854,1651(\mathrm{C}=\mathrm{C})$,
$1487,1427,1101,1041,989,869 \mathrm{~cm}^{-1} ;{ }^{1} \mathrm{H}$ and ${ }^{13} \mathrm{C}$ NMR data according to [16]; EI-MS $m / z 288[\mathrm{M}]^{+}$.

ent-16ß-hydro-kauran-17-oic acid (3): White needles (Hexane$\mathrm{CHCl}_{3}$ 7:3); mp 193-194.0 ${ }^{\circ} \mathrm{C}$ (lit. 192.0-194.0 ${ }^{\circ} \mathrm{C}$ ) [19]; [ $\left.\alpha\right]_{\mathrm{D}}{ }^{20}-63.2^{\circ}$ (c $\left.0.7, \mathrm{CHCl}_{3}\right)$; IR, and ${ }^{1} \mathrm{H}$ and ${ }^{13} \mathrm{C}$ NMR data, according to [19]; EI-MS $\mathrm{m} / z 304[\mathrm{M}]^{+}$.

\section{General experimental procedures}

Melting points (m.p.) were measured on a Microquímica MQAPF 301 apparatus (Palhoça, Santa Catarina, Brazil). IR spectra were acquired in $\mathrm{KBr}$ pellets on a Shimadzu IR Prestige-21 spectrophotometer (Kyoto, Kyoto, Japan). Optical rotations were recorded in $\mathrm{CHCl}_{3}$ on a Jasco P-2000 polarimeter (Hachioji, Tokyo, Japan). GC-MS analyses were performed on a Shimadzu QP5050A GC-MS system (Kyoto, Kyoto, Japan) equipped with an AOC$20 \mathrm{i}$ auto-injector. The separation of the compounds was achieved employing on $\mathrm{RTx}^{\mathbb{}}{ }^{\mathrm{B}}$-5SilMS fused capillary chromatography column $(30 \mathrm{~m} \times 0.25 \mathrm{~mm} \times 0.25 \mu \mathrm{m}$ film thickness) coated with 5\%-diphenyl95\%-dimethylpolysiloxane (Restek, Bellefonte, PA). The column temperature program was $200^{\circ} \mathrm{C} / 5 \mathrm{~min}$, a rate of $10^{\circ} \mathrm{C} / \mathrm{min}$ to $320^{\circ} \mathrm{C}$, and then $320^{\circ} \mathrm{C} / 10 \mathrm{~min}$ (27 min total time analysis); carrier gas, $\mathrm{He}$ (99.999\%; $1.2 \mathrm{~mL} / \mathrm{min}$ ); split ratio, 1:20; injection volume, $0.5 \mathrm{~mL}$ of the compound in $\mathrm{CH}_{2} \mathrm{Cl}_{2}(5.0 \mathrm{mg} / \mathrm{mL})$. MS were taken at $70 \mathrm{eV}$ with a scan interval of $0.5 \mathrm{~s}$ and fragments from 40-500 Da. Low Resolution Mass Spectra (LRMS) were determined using an ultra-high performance chromatography-mass spectrometry system (Acquity UHPLC-TQD - Waters) with an ESI and APCI source in the positive and negative ion mode (Milford, Massachusetts). 1D and 2D NMR data were recorded at $303 \mathrm{~K}_{\text {in }} \mathrm{CDCl}_{3}$ on a Bruker Avance III $600 \mathrm{NMR}$ spectrometer (Karlsruhe, Baden-Württemberg, Germany), operating at $14.1 \mathrm{Tesla}$, observing ${ }^{1} \mathrm{H}$ and ${ }^{13} \mathrm{C}$ at 600 and $150 \mathrm{MHz}$, respectively. The spectrometer was equipped with a $5 \mathrm{~mm}$ multinuclear inverse detection probe (1D and 2D NMR experiments) with $z$-gradient. One-bond and long-range ${ }^{1} \mathrm{H}-{ }^{13} \mathrm{C}$ correlation from HSQC and HMBC NMR experiments were optimized for an average coupling constant ${ }^{1} J_{(\mathrm{C}, \mathrm{H})}$ and ${ }^{\mathrm{LR}} J_{(\mathrm{C}, \mathrm{H})}$ of 140 and $8 \mathrm{~Hz}$, respectively. All ${ }^{1} \mathrm{H}$ and ${ }^{13} \mathrm{C}$ NMR chemical shifts $(\delta)$ are given in ppm related to the TMS signal at $0.00 \mathrm{ppm}$ as an internal reference, and the coupling constants $(J)$ in Hz. Silica gel 60 (70-230 mesh) was used for column chromatography (Fluka Analytical, Schnelldorf, Bavaria, Germany), while silica gel 60 $\mathrm{F}_{254}$ was used for analytical $(0.25 \mathrm{~mm})$, and preparative $(1.00 \mathrm{~mm})$ TLC (Merck, Darmstadt, Germany). Compounds were visualized by exposure under $\mathrm{UV}_{254 / 365}$ light and spraying of anisaldehyde reagent (Neon, São Paulo, SP, Brazil) followed by heating on a hot plate.

\section{Animals}

$\mathrm{BALB} / \mathrm{c}$ and C57BL/6 female mice (6 to 10 weeks old) were bred and maintained at the Gonçalo Moniz Research Center (Oswaldo Cruz Foundation, Bahia, Brazil) in sterilized cages, under a controlled environment and receiving a balanced rodent diet and water ad libitum. All animal experiments and procedures were approved by the institution's committee on the ethical handling of laboratory animals (Approved number: 011/2011).

\section{Drugs}

Gentian violet (Synth, São Paulo, SP, Brazil) was used as positive control in the cytotoxicity assays. Dexamethasone (Sigma-Aldrich, St. Louis, MO), a synthetic glucocorticoid, was used as positive control in immunomodulatory assays. All compounds were dissolved in DMSO (Sigma-Aldrich) and diluted in cell culture medium for use in the assays. The final concentration of DMSO was less than $1 \%$ in all experiments.

\section{Cytotoxicity to mammalian cells}

To determine the cytotoxicity of the hexane extract and isolated compounds, the murine macrophage-like cell line J774 were seeded into 96-well plates at a cell density of $1 \times 10^{4}$ cells/well in Dulbecco's modified Eagle medium (DMEM; Life Technologies, GIBCO-BRL, Gaithersburg, MD) supplemented with $10 \%$ fetal bovine serum 
(FBS; GIBCO), and $50 \mu \mathrm{g} / \mathrm{mL}$ of gentamycin (Novafarma, Anápolis, $\mathrm{GO}$, Brazil) and incubated for $24 \mathrm{~h}$ at $37^{\circ} \mathrm{C}$ and $5 \% \mathrm{CO}_{2}$. After that time each test inhibitors were added at least in five concentrations in triplicate and incubated for $72 \mathrm{~h}$. Twenty $\mu \mathrm{L} /$ well of Alamar Blue (Invitrogen, Carlsbad, CA) was added to the plates during 6 h. Colorimetric readings were performed at 570 and $600 \mathrm{~nm} . \mathrm{CC}_{50}$ values (Cytotoxicity concentration at 50\%) were calculated using data-points gathered from three independent experiments.

\section{Measurement of cytokine and nitric oxide concentrations on macrophages}

For cytokine and nitric oxide determinations, J774 cells were plated in 96-well tissue culture plates at $2 \times 10^{5}$ cells/well in DMEM medium supplemented with $10 \%$ of FBS and $50 \mu \mathrm{g} / \mathrm{mL}$ of gentamycin for $2 \mathrm{~h}$ at $37^{\circ} \mathrm{C}$ and $5 \% \mathrm{CO}_{2}$. Cells were then stimulated with LPS (500 ng/mL, Sigma-Aldrich) plus IFN- $\gamma$ ( $5 \mathrm{ng} / \mathrm{mL}$; SigmaAldrich) in the absence or presence of natural products in testing or dexamethasone at different concentrations, and incubated at $37^{\circ} \mathrm{C}$ Cell-free supernatants were collected $4 \mathrm{~h}$ (for TNF- $\alpha$ measurement) and $24 \mathrm{~h}$ (for IL-1 $\beta$, IL- 6 and IL-10 quantification) and kept at $-80^{\circ} \mathrm{C}$. Cytokine concentrations in supernatants from J774 cultures were determined by enzyme-linked immunosorbent assay (ELISA), using the DuoSet kit from R\&D Systems (Minneapolis, MN), according to the manufacturer's instructions. Quantification of nitric oxide was done using the Griess method [20].

\section{Splenocyte proliferation}

$\mathrm{BALB} / \mathrm{c}$ splenocyte suspensions were prepared in DMEM medium supplemented with $10 \%$ of FBS and $50 \mu \mathrm{g} / \mathrm{mL}$ of gentamycin. Splenocytes were cultured in 96-well plates at $1 \times 10^{6}$ cells/well, in triplicate, in the presence of concanavalin A (Con A; $2 \mu \mathrm{g} / \mathrm{mL}$, SigmaAldrich), alone or in various concentrations of natural products in testing, as described in figure legends. After $48 \mathrm{~h}$ of incubation, $1 \mu \mathrm{Ci}$ of ${ }^{3} \mathrm{H}$ - thymidine (Perkin Elmer, Waltham, MA) was added to each well, and the plate was returned to the incubator for more $18 \mathrm{~h}$. The plate was then transferred to a $\beta$-plate counter (Multilabel Reader, Finland) and the ${ }^{3} \mathrm{H}$-thymidine uptake was measured. Dexamethasone was used as a positive control. Cell-free supernatants were collected after $24 \mathrm{~h}$ of incubation and stored at $-20^{\circ} \mathrm{C}$ for cytokine analysis. IL- 2 and IFN $-\gamma$ concentrations in supernatants from splenocyte cultures were determined by ELISA, as described above.

\section{Mixed lymphocyte reaction (MLR)}

$\mathrm{BALB} / \mathrm{c}$ mice were weekly immunized with intraperitoneal injection of $10^{7}$ splenocytes obtained from C57BL/6 as previously described [21]. After 3 weeks of immunization, mice were euthanized for spleen cell preparation in DMEM medium supplemented with 10 $\%$ of FBS and $50 \mu \mathrm{g} / \mathrm{mL}$ of gentamycin. Spleen cells were plated in 96 well plates at a cell density of $1 \times 10^{6}$ cells/well in the absence or in the presence of irradiated C57BL/6 splenocytes at $10^{6}$ cells/well (dose of 3 Gy in a ${ }^{137} \mathrm{Cs}$ source irradiator purchased from CisBio International Cordolet, France) and different concentrations of AVHR, in triplicates. After $72 \mathrm{~h}$ of incubation, ${ }^{3} \mathrm{H}$-thymidine was added to each well, and the plate was returned to the incubator for more $18 \mathrm{~h}$. The plate was then transferred to a $\beta$-plate counter and the ${ }^{3} \mathrm{H}$-thymidine uptake was measured.

\section{Cell cycle analysis}

Splenocytes from BALB/c mice were plated at a cell density of $5 \times 10^{6}$ cells/well in $1 \mathrm{~mL}$ of complete medium containing $5 \mu \mathrm{g} / \mathrm{mL}$ of Con $\mathrm{A}$ in the absence or presence of different concentrations of $\operatorname{AVHR}(5,10$ and $20 \mu \mathrm{g} / \mathrm{mL})$ for $48 \mathrm{~h}$. Cells were centrifuged and then pellet was washed twice with cold PBS and resuspended in a solution of PBS with propidium iodide $(2 \mu \mathrm{g} / \mathrm{mL})$ and $0.1 \%$ of Triton $\mathrm{X}-100$ at $37^{\circ} \mathrm{C}$ for $30 \mathrm{~min}$. The cells were analyzed for cell cycle using flow cytometry (FACS Calibur, BD Biosciences, San Jose, CA). Cell debris and clumps were gated out, and PreG1, G0/G1, S and G2/M populations were quantified using Cell Quest software.
Table 1: Cytotoxicity against $\mathrm{J} 774$ macrophages of the natural products of $A$. vepretorum.

\begin{tabular}{|c|c|}
\hline Sample & CC $_{50}$ \\
\hline AVHR & 39.3 \\
\hline $\mathbf{1}$ & $29.4(97.3)$ \\
\hline $\mathbf{2}$ & $26.1(90.5)$ \\
\hline $\mathbf{3}$ & $56.2(184.5)$ \\
\hline Dexamethasone $^{\text {Gentian violet }}{ }^{\mathrm{a}}$ & $35.7(91.1)$ \\
\hline Geil & $0.3(0.8)$ \\
\hline
\end{tabular}

Data are presented as $\mathrm{CC}_{50}$ values in $\mu \mathrm{g} / \mathrm{mL}(\mu \mathrm{M})$ obtained from three independent experiments. ${ }^{a}$ Positive control in the cytotoxicity assays. $\mathrm{CC}_{50}=$ Cytotoxicity concentration at $50 \%$.

Statiscal analysis were performed by one-way analysis of variance and Newman-Keuls multiple comparison tests using Graph Pad Prism version 5.01 (Graph Pad Software, San Diego, CA). Differences were considered significant when the values of $P$ were $<0.05$.

\section{Results}

The plant extract was evaluated against mammalian cells to determine the cytotoxicity. The hexane extract showed a $\mathrm{CC}_{50}$ value of $39.3 \mu \mathrm{g} / \mathrm{mL}$ and non cytotoxic in concentrations lower than $25 \mu \mathrm{g} / \mathrm{mL}$ (Table 1). Therefore, concentrations lower than $25 \mu \mathrm{g} / \mathrm{mL}$ were used as the concentrations of the extract in the subsequent experiments.

To assess the effects of AVHR on macrophages, proinflammatory mediators production was evaluated. The treatment with the hexane extract $(5,10$ or $20 \mu \mathrm{g} / \mathrm{mL})$ significantly decreased the production of nitric oxide, TNF- $\alpha$, IL- $1 \beta$ and IL- 6 , as well as the treatment with dexamethasone $(20 \mu \mathrm{g} / \mathrm{mL})$ compared to untreated and stimulated cultures (Figure 1A, Figure 1B, Figure 1C, and Figure 1D). The cell-free supernatant was also used to quantify IL-10, however, the treatment with AVHR didn't increase the levels of this cytokine (data not shown).

The action of the hexane extract on lymphocyte activation was also analyzed. Addition of plant extract in Con A-induced lymphocyte proliferation assays and MLR cultures of spleen cells of BALB/c mice stimulated with C57BL/6 cells also caused a significant inhibition of proliferation greater than $90 \%$ (Figure 2A, and Figure 2B). The cellfree supernatant of cultures of splenocytes stimulated with Con A and treated with hexane extract or dexamethasone was also investigated to understand the effect of compounds on cytokines production by lymphocytes. As shown in figure $2 \mathrm{C}$ and figure $2 \mathrm{D}$, the treatment with various concentrations of AVHR significantly decreases the secretion of IL- 2 and IFN- $\gamma$ compared with untreated and stimulated cultures. Under the same conditions, dexamethasone also promotes a high decrease in cytokines production.

The effect of AVHR on cell-cycle progression of splenocytes revealed arrested splenocytes on G0/G1 phase, which was accompanied by an increase in PreG1 phase. Importantly, these effects were in a concentration-dependent manner (Figure 3 ).

Finally, phytochemical investigation of AVHR led to the isolation and characterization of three diterpenes belonging to entkaurane series, identified as ent-kaur-16-en-19-oic acid (1), ent-3 $\beta$ hydroxykaur-16-ene (2) and ent-16 $\beta$-hydro-kauran-17-oic acid (3) (Figure 4).

All isolated compounds showed low cytotoxicity to J774 macrophages with values of $\mathrm{CC}_{50}$ above $90 \mu \mathrm{M}$ (Table 1 ). When tested in cultures of J774 macrophages stimulated with LPS and IFN- $\gamma$, the compounds were able to reduce the production of nitric oxide, especially compounds 1 and 2 in highest concentration $(50 \mu \mathrm{M})$ (Figure 5A). Regarding the immunosuppressive effect on lymphocyte proliferation, compound 2 showed the best profile with a significantly inhibition of lymphoproliferation at the concentrations of 50 and 25 $\mu \mathrm{M}$ (Figure 5B).

\section{Discussion}

Despite its use in folk medicine, little is known about the 
A

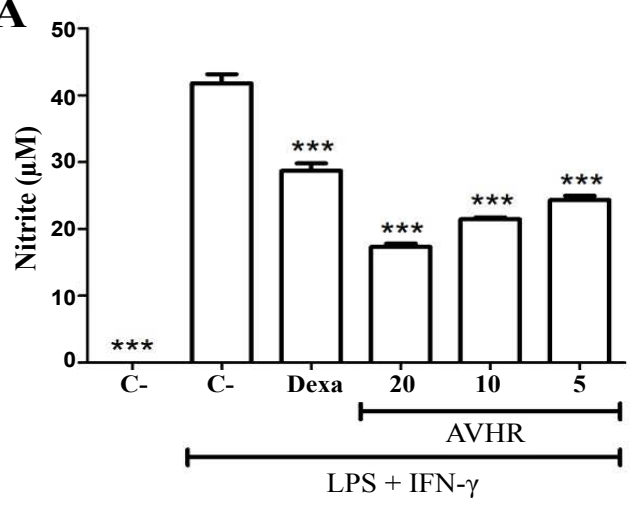

C

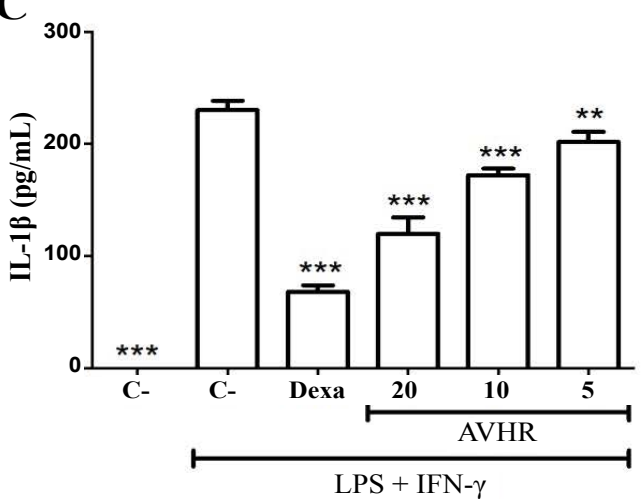

B

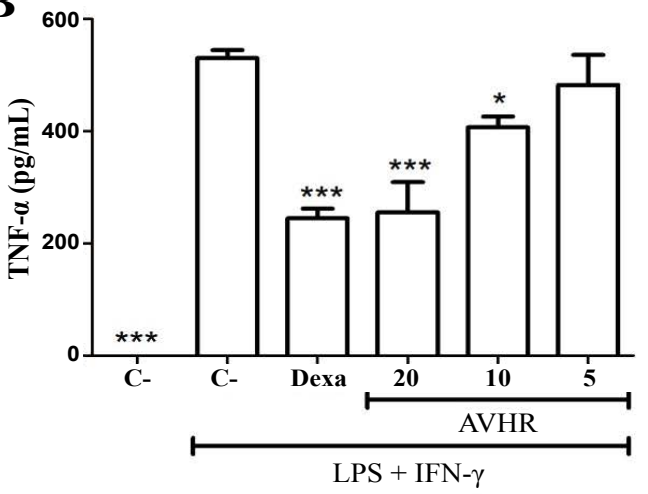

D

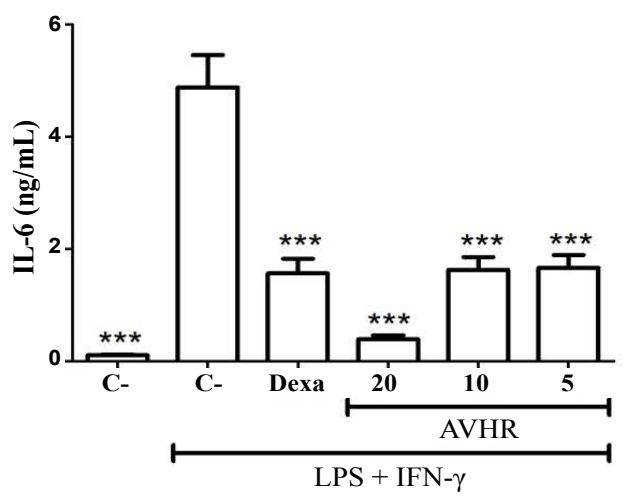

Figure 1: Assessment of nitric oxide and cytokine production by $J 774$ macrophages treated with AVHR. Effect of AVHR (20, 10 or $5 \mu \mathrm{g} / \mathrm{mL})$ or dexamethasone $(20 \mu \mathrm{g} / \mathrm{mL}$ ) on nitric oxide (A); TNF- $\alpha$ (B); IL-1 $\beta$ (C) and IL-6 (D) production. Values represent the means \pm SEM of four determinations obtained in one of two experiments performed. ${ }^{* * *} P<0.001 ;{ }^{* *} P<0.01 ;{ }^{*} P<0.05$ compared to untreated and stimulated cultures.

A

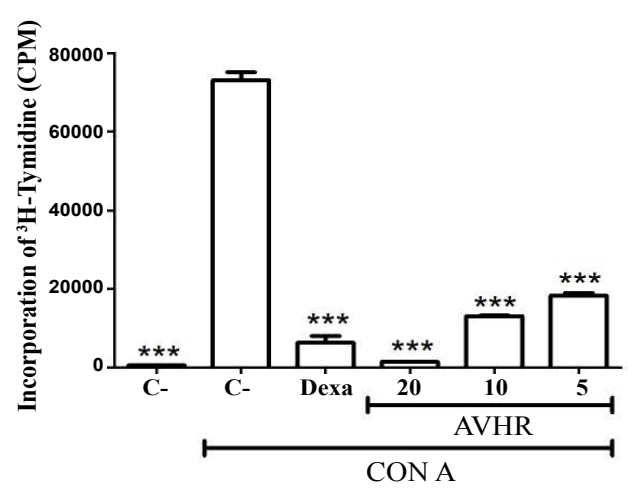

C

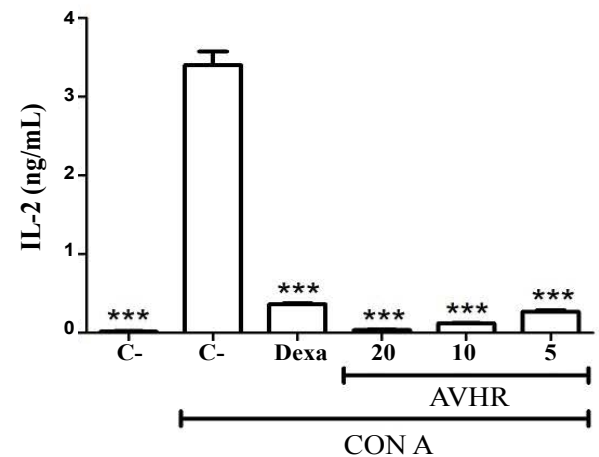

B

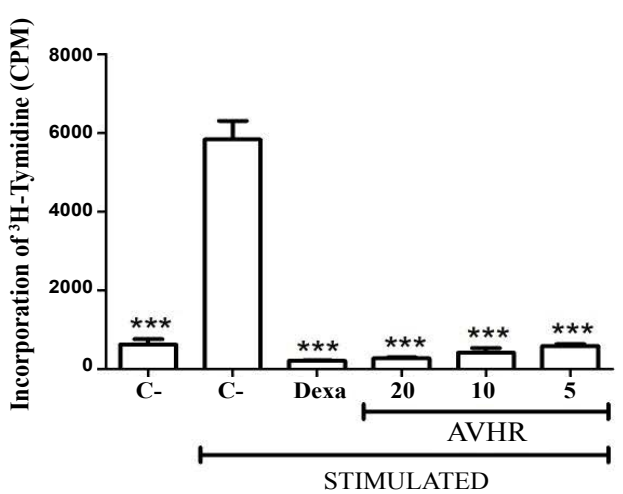

D

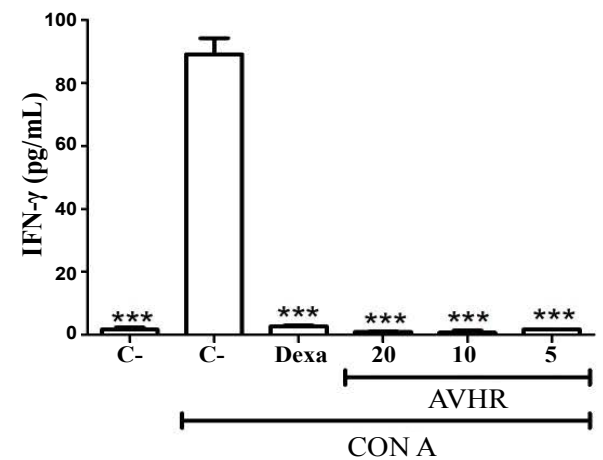

Figure 2: Inhibition of lymphocyte proliferation and cytokine production by AVHR. (A) Effect of treatment with AVHR (20, $10 \mathrm{or} 5 \mu \mathrm{g} / \mathrm{mL})$ or dexamethasone $(20 \mu \mathrm{g} / \mathrm{mL})$ for $48 \mathrm{~h}$ on Con A-induced lymphoproliferation; (B) Splenocytes from BALB/c mice sensitized with C57BL/6 cells were cultured in the absence (unstimulated) or presence (stimulated) of irradiated C57BL/6 spleen cells, without or with AVHR $(20,10$ or $5 \mu \mathrm{g} / \mathrm{mL})$ or dexamethasone $(20 \mu \mathrm{g} / \mathrm{mL})$ for $72 \mathrm{~h}$. Concentrations of IFN-y; (C) IL-2; (D) were determined in splenocytes treated or not with AVHR or dexamethasone after $24 \mathrm{~h}$ of treatment. Values represent the means \pm S.E.M. of 4 determinations. ${ }^{* * *} P<0.001$ compared to untreated and stimulated cultures. 


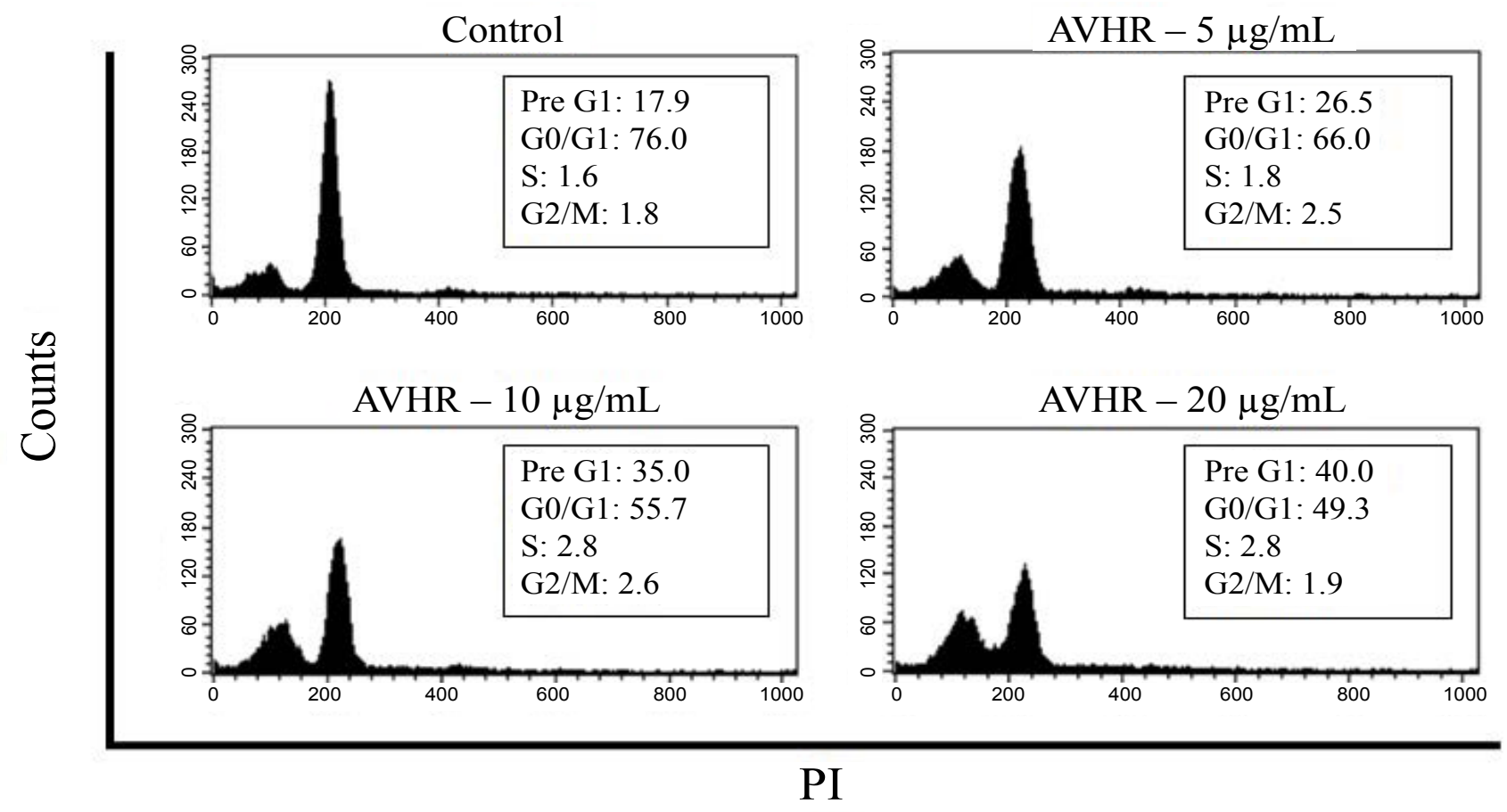

Figure 3: Analysis of cell cycle progression after treatment with AVHR. Splenocytes were untreated or treated with AVHR (20, 10 or $5 \mu \mathrm{g} / \mathrm{mL})$ for $48 \mathrm{~h}$. The distribution and percentage of cells in pre-phase, G0/G1, S and G2/M phase of the cell cycle are indicated.

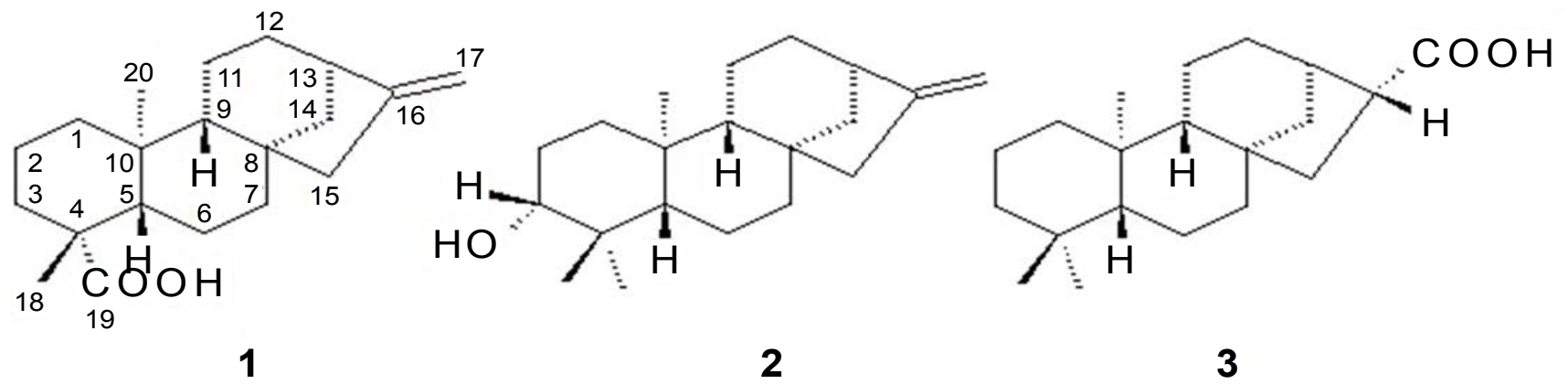

Figure 4: Chemical structures of ent-kaurane diterpenes isolated from the roots of $A$. vepretorum.

A

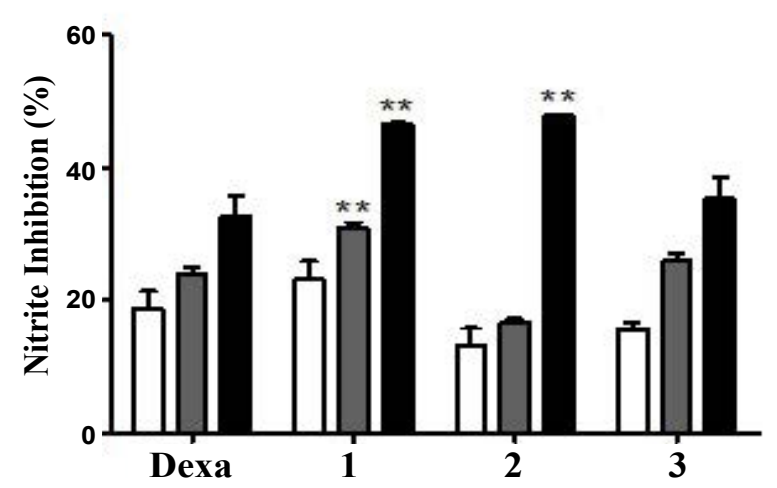

B

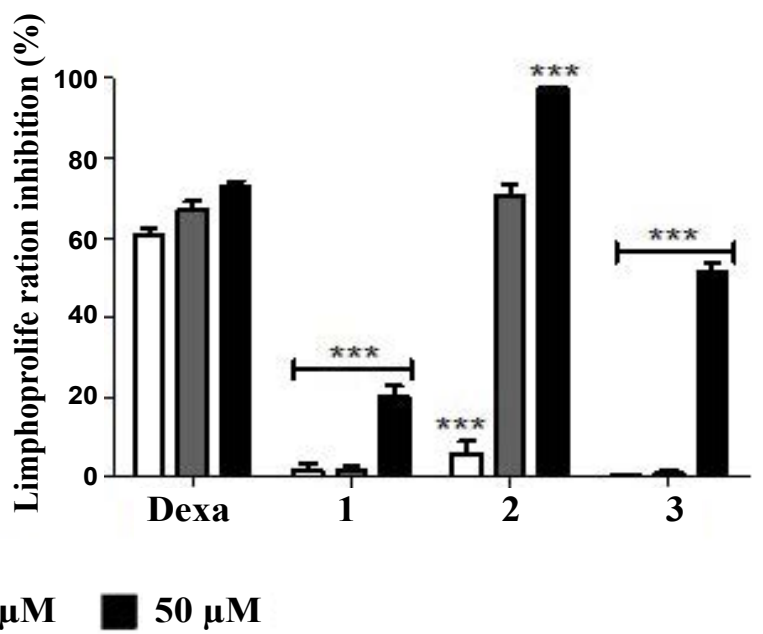

Figure 5: Effect of ent-kaurane diterpenes isolated from the roots of $A$. vepretorum on NO production and lymphoproliferation. (A) Comparison of nitric oxide inhibition by different isolated compounds from roots of $A$. vepretorum; (B) Comparison of Con A-induced lymphoproliferation inhibition by different isolated compounds from roots of $A$. vepretorum Values represent the means \pm S.E.M. of 4 determinations obtained in one of two experiments performed. ${ }^{* * *} P<0.001$; ${ }^{*} P<0.01 ;{ }^{*} P<0.05$ compared to cultures treated with dexamethasone in the same concentration. 
immunomodulatory properties of Annona vepretorum. In this report, the immunomodulatory activiy of a hexane extract and isolated compounds from roots of $A$. vepretorum was demonstrated.

Macrophages are a population of immune cells that have a range of roles in both the induction and resolution of inflammation mainly through the secretion of cytokines [22]. Pro-inflammatory mediators such as TNF- $\alpha$, IL- $1 \beta$, IL- 6 and nitric oxide are well-recognized by participate in various inflammatory diseases [22]. TNF- $\alpha$ is a key mediator on inflammation establishment by recruiting and activating macrophages and $\mathrm{T}$ cells and favoring the secretion of other proinflammatory cytokines [23]. IL- $1 \beta$ has similar effects to TNF- $\alpha$ and on high concentrations leads to cell death or tissue injury [24]. IL-6 has a majority contribution on the production of most acute-inflammatory proteins. Nitric oxide due to over production on inflammatory conditions promotes vasodilatation, vascular permeability and edema, signs of acute inflammation [25]. Through Griess method and cytokine measurement by ELISA was shown a potent effect of hexane extract from roots of $A$. vepretorum on inhibition of nitric oxide production and pro-inflammatory cytokines on macrophages stimulated with LPS plus IFN- $\gamma$. Moreover, these results are in agreement with previous studies with an ethanolic extract of $A$. vepretorum, that showed the ability of extract in inhibit leukocyte migration on peritoneal cavity induced by injection of carrageenan and reduce paw edema induced by carrageenan or histamine [17]. Both models are well recognized to evaluate anti-inflammatory effects and involved participation of chemical mediators and cytokines such as nitric oxide, IL-1 $\beta$, IL- 6 and TNF- $\alpha[17,26]$. These data reinforce the potential of AVHR on inflammatory conditions, once the extract inhibits these chemical mediators and cytokines production on activated macrophages.

A promising immunosuppressive activity on lymphocytes was also observed on AVHR. The plant extract was able to inhibit lymphocyte proliferation induced by Con A and allospecific lymphocyte proliferation, indicating that inhibition was not a nonspecific phenomenon due to interference on the interaction of ConA with surface molecules on spleen cells [21]. Flow cytometry analysis of cell cycle by propidium iodide staining reinforced the effect of the hexane extract on lymphoproliferation, since it was observed that extract treatment blocked cell-cycle progression by arresting cells at G0/G1 phase. Moreover, AVHR reduced IL- 2 and IFN- $\gamma$ production, key cytokines on lymphocyte proliferation and activation [27]. In fact, the antiproliferative activity of this specie is well recognized in different lineages of tumor cells, especially in leukemia lineages such as HL60 and K562 cells [16,28]. Furthermore, the in vivo efficacy of an essential oil from $A$. vepretorum was demonstrated in mice inoculated with B16-F10 mouse melanoma [28].

Finally, phytochemical investigations of AVHR culminate with the isolation and characterization of three diterpenes belonging to ent-kaurane series. These compounds have been described for the first time in the roots of $A$. vepretorum, however compounds 1 and 2 recently were described in the stem bark of this specie, indicating that the plant accumulates these compounds in different part, such as stem bark and root [16]. These compounds are well represented in family Annonaceae found in different species, particularly in the species of the genus Annona and Xylopia and considered as chemotaxonomic markers [18,29]. Previous biological investigations described the cytotoxicity effects of 1 and 2 on different tumor cell lines [16]. Here, it was demonstrated the immunomodulatory effects of these diterpenes, especially the compound 2 , on the inhibition of nitric oxide production and lymphoproliferation. Previous reports, also demonstrated the immunomodulatory effects of others entkaurane on the inhibition of nitric oxide production in RAW264.7 macrophages [30,31]. Moreover, the anti-inflammatory activity of 1 on an in vivo model of paw edema induced by carrageenan was also reported, reinforcing this class of compounds as a promising source for obtaining immunomodulatory drugs [32].

However, the isolated diterpenes showed a weak activity when compared with AVHR, suggesting that the higher potency of extract may be attributed to other compounds present in its composition or a synergistic effect of some of its components.

\section{Conclusion}

The present work suggests a potent immunomodulatory activity of hexane extract from roots of $A$. vepretorum and isolated diterpenes belonging to ent-kaurane series. The extract and isolated compounds inhibited cytokine production and cell cycle development. Therefore, the investigation of other members of this family is important.

\section{Acknowledgements}

This work was supported by CNPq, PRONEX and FASPEB.

\section{Conflict of Interest Statement}

None of the authors have any financial or personal relationships that could inappropriately influence or bias the content of the paper.

\section{References}

1. Chung HY, Cesari M, Anton S, Marzetti E, Giovannini S, et al. (2009) Molecular inflammation: underpinnings of aging and age-related diseases. Ageing Res Rev 8: 18-30.

2. Salinas GF, Braza F, Brouard S, Tak PP, Baeten D (2013) The role of B lymphocytes in the progression from autoimmunity to autoimmune disease. Clin Immunol 146: 34-45.

3. Korhonen R, Lahti A, Kankaanranta H, Moilanen E (2005) Nitric oxide production and signaling in inflammation. Curr Drug Targets Inflamm Allergy 4: $471-479$

4. Perez-Sepulveda A, Torres MJ, Khoury M, Illanes SE (2014) Innate immune system and preeclampsia. Front Immunol 5: 244.

5. Newman DJ, Cragg GM (2012) Natural products as sources of new drugs over the 30 years from 1981 to 2010. J Nat Prod 75: 311-335.

6. Kumar, SV, Kumar SP, Rupesh D, Nitin K (2011) Immunomodulatory effects of some traditional medicinal plants. J Chem Pharm Res 3: 675-684.

7. Ma HD, Deng YR, Tian Z, Lian ZX (2013) Traditional Chinese medicine and immune regulation. Clin Rev Allergy Immunol 44: 229-241.

8. Rastogi S, Pandey MM, Kumar Singh Rawat A (2015) Medicinal plants of the genus Betula--traditional uses and a phytochemical-pharmacological review. J Ethnopharmacol 159: 62-83.

9. Costa EV, Dutra LM, Nogueira PC, Moraes VR, Salvador MJ, et al. (2012) Essential oil from the leaves of Annona vepretorum: chemical composition and bioactivity. Nat Prod Commun 7: 265-266.

10. Gupta RK, Kesari AN, Watal G, Murthy PS, Chandra R, et al. (2005) Nutritional and hypoglycemic effect of fruit pulp of Annona squamosa in normal healthy and alloxan-induced diabetic rabbits. Ann Nutr Metab 49: 407-413.

11. Costa EV, Dutra LM, Salvador MJ, Ribeiro LH, Gadelha FR, et al. (2013) Chemical composition of the essential oils of Annona pickelii and Annona salzmannii (Annonaceae), and their antitumour and trypanocidal activities. Nat Prod Res 27: 997-1001.

12. Meira CS, Guimarães ET, Macedo TS, Silva TB, Menezes LRA, et al. (2015) Chemical composition of essential oils from Annona vepretorum Mart. and Annona squamosa L. (Annonaceae) leaves and their antimalarial and trypanocidal activities. J Essent Oil Res 27: 160-168.

13. Alali FQ, Liu XX, McLaughlin JL (1999) Annonaceous acetogenins: recent progress. J Nat Prod 62: 504-540.

14. Foong CP, Hamid RA (2012) Evaluation of anti-inflammatory activities of ethanolic extract of Annona muricata leaves. Braz J Pharmacogn 22: 13011307.

15. Dholvitayakhun A, Cushnie TP, Trachoo N (2012) Antibacterial activity of three medicinal Thai plants against Campylobacter jejuni and other foodborne pathogens. Nat Prod Res 26: 356-363.

16. Dutra LM, Bomfim LM, Rocha SL, Nepel A, Soares MB, et al. (2014) entKaurane diterpenes from the stem bark of Annona vepretorum (Annonaceae) and cytotoxic evaluation. Bioorg Med Chem Lett 24: 3315-3320.

17. Silva JC, Araújo Cde S, de Lima-Saraiva SR, de Oliveira-Junior RG, Diniz TC et al. (2015) Antinociceptive and anti-inflammatory activities of the ethanolic extract of Annona vepretorum Mart. (Annonaceae) in rodents. BMC Complement Altern Med 15: 197.

18. Wu YC, Hung YC, Chang FR, Cosentino M, Wang HK, et al. (1996) Identification of ent-16ß,17-Dihydroxykauran-19-oic acid as an anti-HIV principle and isolation of the new diterpenoids annosquamosins $A$ and $B$ from Annona squamosa. J Nat Prod 59: 635-637. 
19. Hsieh TJ, Wu YC, Chen SC, Huang CS, Chen CY (2004) Chemical constituents from Annona glabra. J Chin Chem Soc 51: 869-876.

20. Green LC, Wagner DA, Glogowski J, Skipper PL, Wishnok JS, et al. (1982) Analysis of nitrate, nitrite, and $[15 \mathrm{~N}]$ nitrate in biological fluids. Anal Biochem 126: $131-138$.

21. Soares MB, Brustolim D, Santos LA, Bellintani MC, Paiva FP, et al. (2006) Physalins $B, F$ and $G$, seco-steroids purified from Physalis angulata $L$., inhibit lymphocyte function and allogeneic transplant rejection. Int Immunopharmacol 6: 408-414.

22. Dey A, Allen J, Hankey-Giblin PA (2015) Ontogeny and polarization of macrophages in inflammation: blood monocytes versus tissue macrophages. Front Immunol 5: 683.

23. Elenkov IJ, lezzoni DG, Daly A, Harris AG, Chrousos GP (2005) Cytokine dysregulation, inflammation and well-being. Neuroimmunomodulation 12 : 255-269.

24. Gabay C, Kushner I (1999) Acute-phase proteins and other systemic responses to inflammation. N Engl J Med 340: 448-454.

25. Xu J, Jia YY, Chen SR, Ye JT, Bu XZ, et al. (2013) (E)-1-(4-ethoxyphenyl) 3-(4-nitrophenyl)-prop-2-en-1-one suppresses LPS-induced inflammatory response through inhibition of NF-kB signaling pathway. Int Immunopharmacol 15: $743-751$
26. Loram LC, Fuller A, Fick LG, Cartmell T, Poole S, et al. (2007) Cytokine profiles during carrageenan-induced inflammatory hyperalgesia in rat muscle an hind paw. Pain 8: 127-136.

27. Abbas AK, Murphy KM, Sher A (1996) Functional diversity of helper T lymphocytes. Nature 383: 787-793.

28. Bomfim LM, Menezes LR, Rodrigues AC, Dias RB, Rocha CA, et al. (2016) Antitumour Activity of the Microencapsulation of Annona vepretorum Essential Oil. Basic Clin Pharmacol Toxicol 118: 208-213.

29. Leboeuf M, Cavé A, Bhaumik PK, Mukherjee B, Mukherjee R (1982) The phytochemistry of the Annonaceae. Phytochemistry 21: 2783-2813.

30. Aquila S, Weng ZY, Zeng YQ, Sun HD, Ríos JL (2009) Inhibition of NFkappaB activation and iNOS induction by ent-kaurane diterpenoids in LPS stimulated RAW264.7 murine macrophages. J Nat Prod 72: 1269-1272.

31. Nhiem NX, Hien NT, Tai BH, Anh Hle T, Hang DT, et al. (2015) New entkauranes from the fruits of Annona glabra and their inhibitory nitric oxide production in LPS-stimulated RAW264.7 macrophages. Bioorg Med Chem Lett 25: 254-258.

32. Chavan MJ, Kolhe DR, Wakte PS, Shinde DB (2012) Analgesic and antiinflammatory activity of kaur-16-en-19-oic acid from Annona reticulata L. bark. Phytother Res 26: 273-276. 